weniger betragen, als zur Fällung gehört, die man zuletat durch vorsichtigen Zusatz von kohlensaurem Kali vollständig macht. Wärme oder Kochen ist zur Fällung nicht nöthig. Der breiartig aufgequollene Niederschlag ist oder erscheint in seiner Masse sehr ungleichformig; wenn man ihn aber über Nacht sich selbst überlïsst, unter jeweiligem Umrühren, so vereinigt sich das $O x y-$ dul mit dem Oxyd ganz vollkommen zu Aethiops martialis, den man durch 2- bis 3maliges Aussüssen von allem Jodkalium befreien kann. Da alle Methoden durch Schmelzung Verluste nach sich ziehen, die sich kaum vermeiden lassen, so dürfte die eben beschriebene $\mathrm{Ab}$ änderung wohl bald allgemein Anwendung finden. (Buchner's neues Repert. Bd. 6 . Heft 3.)

B.

\title{
Ueber die gleiche Zusammensetzung des Leukophans und Melinophans, so wie über einige neue Verbin- dungen aus dem Salzlager von Stassfurt.
}

Der Leukophan ist ein seltenes Mineral aus dem norwegischen Zirkonsyenit, von Esmark aufgefunden und dann von A. Erdmann chemisch untersucht, wonach es eine neue und ungewöhnliche Zusammensetzung hat, indem es eine Verbindung von kieselsaurer Beryllerde und Kalkerde mit Fluornatrium ist.

Ein aus derselben Gegend stammendes gelbes und Anfangs für Wöhlerit gehaltenes Mineral ist neuerlich von Scheerer auf Grund einer Analyse von Richter als Melinophan bezeichnet worden. Indem Scheerer es mit dem Leukophan vergleicht, kommt er zu dem Schlusse, beide möchten analoge Verbindungen, die Beryllerde des Leukophans aber in Melinophan durch Thonerde ersetzt, auch eine kleinere Menge Fluornatrium in letzterem enthalten sein.

Vergleichende Analysen beider Mineralien haben $R$ ammelsberg überzeugt, dass A. Erdmann's Resultat in Betreff des Leukophans genau ist, dass aber Richter's Angaben für den Melinophan ungenau sind. Beide enthalten vorherrschend Beryllerde, neben wenig Thonerde, und wenn in den relativen Mengen der Säure, des Kalkes, Natrons und Fluors sich Differenzen finden, so sind dieselben doch nicht so gross, dass sie das Resultat der Berechnung trüben könnten, wonach die $\mathrm{Zu}$ sammensetzung beider dieselbe ist. 
In den oberen Teufen des Steinsalzlagers von Stassfurt hat sich neben Stassfurtit, Carnallit, Anhydrit etc. ein neues höchst zerfliessliches gelbes Salz gefunden, welches eine feste Verbindung von 1 Atom Chlorcaloium, 2 At. Chlormagnesium und $12 \mathrm{At}$. Wasser ist, und für welches Rammelsberg den Namen "Tachhydrit" vorschlägt. Es besitzt deutliche Spaltbarkeit und scheint im Anhydrit eingelagert zu sein, enthält aber keine Spur Schwefelsäure. In seiner Nähe findet sich gleichzeitig weisse, durchscheinende, feinkörnige, schwefelsaure Talkerde mit $1 \mathrm{At}$. Wasser, gemengt mit einigen Procenten Chlornatrium, und also vom gewöhnlichen Bittersalze verschieden. (Ber. der Akad. der Wissensch. zu Berlin. 1856.)

$B$.

\section{Löthrohr mit continuirlichem Luftstrom.}

Chevalier hat das früher von de Luca beschriebene Löthrohr abgeändert; aus der beigefügten Zeichnung ergiebt sich die Construction des verbesserten Instruments.

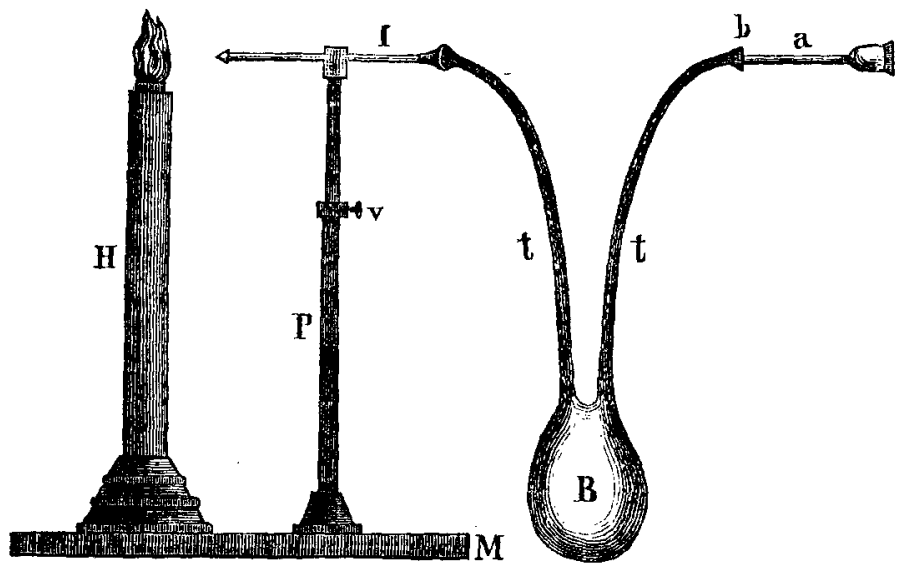

$a$ ist das Mundrohr, durch welches man Luft in den Kautschukballon $B$ bläst, dieser steht durch die Kautschukröhre $t$ mit dem Mundstück in Verbindung; bei $b$ befindet sich eine Klappe, welche hindert, dass die Luft aus dem Ballon wieder durch das Mundrohr entweicht. Durch einè zweite Röhre $t$ ist der Ballon mit der Röhre $I$ verbunden, welche die Luft in die Flamme bläst. 